\title{
A hybrid protein containing MSP1a repeats and Omp7, Omp8 and Omp9 epitopes protect immunized BALB/c mice against anaplasmosis
}

\author{
Alex Sander R. Cangussu ${ }^{1,2^{*}}$, Luis André M. Mariúba ${ }^{3}$, Pritesh Lalwani ${ }^{3}$, Keila Dayane E. S. Pereira ${ }^{3}$, \\ Spartaco Astolphi-Filho', Patricia P. Orlandi ${ }^{3}$, Sabrina Epiphanio ${ }^{4}$, Kelvison F. Viana ${ }^{2}$, Mucio Flavio B. Ribeiro ${ }^{5}$, \\ Hidelberto M. Silva ${ }^{6}$, Claudio R. F. Marinho ${ }^{7}$ and Paulo A. Nogueira ${ }^{3}$
}

\begin{abstract}
Anaplasma marginale (A. marginale) has a remarkable impact on livestock production, and an effective vaccine is not currently available due to the inexistence of a small animal model. Recently, BALB/c mice were successfully infected with $A$. marginale, resulting in an acute and persistent anaplasmosis infection. Here, we designed a hybrid protein containing repeats of polypeptide 1a from major surface protein-1 complex (MSP1a) repeats and common epitopes of outer membrane proteins (OMPs) OMP7, OMP8 and OMP9 expressed in Escherichia coli. Our proof-of-concept assessed vaccinal effectiveness against a challenge with live bacteria. The MSP1a/OMP7/8/9 immunized BALB/C mice exhibited a strong reduction in rickettsemia and had no signs of anaplasmosis or hepatic lesions. In contrast, the nonimmunized mice exhibited signs of anaplasmosis and a body weight loss associated with increases in monocyte and neutrophil counts. Furthermore, the non-immunized mice displayed atrophies with chronic inflammatory infiltrates in the spleen and increased binucleation and hydropic degeneration in the hepatocytes. Our findings demonstrated that immunization with our hybrid protein induced a strong reduction in rickettsemia and conferred protection against anaplasmosis. Therefore, given the strong evidence of the protective effect against anaplasmosis, hybrid protein designs are potential candidates for the rational design of vaccinal subunits.
\end{abstract}

\section{Introduction}

Anaplasma marginale (A. marginale) causes a life-threatening disease with a remarkable impact on human and animal health. Because tick vector control is difficult to achieve and an effective vaccine is nonexistent, anaplasmosis can cause severe economic losses in livestock production in tropical and subtropical regions [1-6]. A. marginale causes anaplasmosis in cattle of all ages, the severity increasing with age [7]. Following initial infection and 7-60 days incubation [1], the number of infected erythrocytes geometrically increases, doubling

\footnotetext{
*Correspondence: alexcangussu@uft.edu.br

${ }^{2}$ Universidade Federal do Tocantins-Engenharia de Bioprocessos e Biotecnologia, Gurupi, TO/Brazil, Brazil

Full list of author information is available at the end of the article
}

approximately every $24 \mathrm{~h}$ [8]. The invaded erythrocytes are phagocytozed by the reticuloendothelial system, causing progressive anemia $[1,7]$. The clinical signs of anaplasmosis include fever, pale mucous membranes, anorexia, weight loss, decreased milk production, lethargy, icterus, gastrointestinal symptoms, miscarriage, and resultant death $[1,5,9,10]$. Histopathological changes due to hypoxic conditions are observed in various organs. Marked thickening of the fat-containing liver capsule and bile retention causes hepatomegaly associated with hepatic hydropic degeneration. In the spleen, areas of lymphoid follicle atrophy associated with histiocytosis and fibrosis in the white pulp area are present [10].

A microscopic analysis is the best method for the diagnosis of anaplasmosis but is not reliable for detecting pre-symptomatic or carrier animals. In these cases, 
serological and molecular detection methods could be indicated [4]. The gold standard for the identification of A. marginale-free blood is the sub-inoculation of blood from the suspect animal into a splenectomized calf; however, this method is costly and raises animal welfare issues. Other methods, such as ELISA tests or PCR methods, have not been formally validated.

Anaplasma marginale establishes itself as a persistent infection that is difficult to control despite the routine use of preventive chemotherapy, but in cases of a carrier state in infected cattle, this intervention is a long-acting antimicrobial treatment [11]. Hence, new strategies are urgently needed for controlling disease spread [12]. Vaccination can be an ideal strategy for not only controlling disease transmission and spread but also for providing animals long-term immunity [2, 9-11, 13-16]. Currently, there are two commercially available vaccines for anaplasmosis; however, these vaccines are ineffective in controlling the epidemic and render animals as immune carriers, making disease control even more challenging. In addition, the presence of heterologous circulating strains and the risk associated with immunizing bulls or heifers with live vaccines enhance the necessity of the development of newer vaccines [17, 18]. Although $A$. marginale vaccines have been commercially available, chemotherapy remains the primary method of anaplasmosis control [11].

Additionally, cell surface proteins in A. marginale have been the focus of vaccine development since studies have shown that immunization with the purified outer membranes conferred protection against anaplasmosis $[14,19,20]$. Among the outer membrane proteins (OMPs), two major surface proteins belong to the MSP1 and MSP2 superfamilies [12, 21, 22]. The N-terminus portion of MSP1a contains tandem repeats that are conserved among $A$. marginale isolates, which have a sufficient effect on the adhesion to bovine erythrocytes and tick cells. The repeated sequences enhanced specific $\mathrm{B}$ and $\mathrm{T}$ cell responses and elicited neutralizing antibodies that conferred protection against anaplasmosis [14, 17, 23, 24]. Heterologous OMPs with conserved epitopes (OMP7-9) were identified using mass spectrometry with material adsorbed with serum IgG against surface complex vaccinates. The omp7-9 genes belong to the msp2 superfamily and are arranged in tandem with a structure that is similar to that of a five-gene operon $[14,23]$. OMP7 to OMP9 are invariant proteins that are known to be expressed at high levels in bovine erythrocytes, and they are components of the outer membrane protein complexes that are capable of inducing complete protection $[14,25]$.

Recently, BALB/c mice were successfully infected with A. marginale, similar to the pathogen Anaplasma phagocytophilum responsible for human granulocytic anaplasmosis [26-28]. In another study, following challenge by Anaplasma spp. isolated from natural hosts, the $\mathrm{BALB} / \mathrm{c}$ mice showed injury and liver inflammation with a direct contribution by neutrophils [10, 29, 30].

Although the signs of anaplasmosis in the murine $A$. marginale model were not identical to those described in humans or ruminants, the BALB/c mice developed an acute and chronic infection [27, 28]. Furthermore, we were able to detect hepatocyte injury and liver inflammation with a direct contribution by neutrophils after a challenge with Anaplasma spp. in natural hosts [10, 29, 30].

In the present study, we employed a murine $A$. marginale model to assess a hybrid protein containing epitopes of major surface protein 1a (MSP1a) and the outer membrane proteins (OMPs) 7-9 as a subunit vaccine against anaplasmosis. Based on clinical signs and histopathological criteria established in acute and chronic infection, our immunogen protected $\mathrm{BALB} / \mathrm{c}$ mice challenged with $A$. marginale strain UFMG2.

\section{Materials and methods \\ Mice}

Seven-week-old female BALB/c mice were bred under pathogen-free conditions in our isogenic mouse facilities, in the Tocantins Federal University, (TO, Brazil). In all experiments, the welfare of the animals was taken in consideration. They were housed in a standard polycarbonate cage of $41 \times 34 \times 16 \mathrm{~cm}$ with wood shavings bedding, and a maximum of five mice per cage. We also attempted to reduce the stress of individual housing (when necessary) by environmental enrichment with nestlets and small play tunnels. The animal room was under controlled temperature and humidity in a light and dark cycle of $12 \mathrm{~h}$. Mice had ad libitum access to food and water.

\section{Anesthesia and euthanasia}

All efforts were made to prevent undue stress or pain to the mice. The mice were humanely euthanized once they show the following clinical signs: lethargy; hypothermia and/or difficulty of breathing. The mice were euthanized with ketamine $(300 \mathrm{mg} / \mathrm{kg})$ (Vetbrands, Brazil) and xylazine $(22.5 \mathrm{mg} / \mathrm{kg}$ ) (Syntec, Brazil). Consciousness was checked by testing the pedal reflex and observing heartbeats and breathing movements. All experiments were performed in accordance with the ethical guidelines for experiments with mice, and the protocols were approved by the National Council for Control of Animal Experimentation, Federal University of Tocantins Animal Experimentation Committee (CEUA No 23101.003595/2015-15). The guidelines for animal use 
and care were based on the standards established by The Brazilian College of Animal Experimentation (COBEA).

\section{Anaplasma UFMG2 infection and challenge}

The strain $A$. marginale UFMG2 and tick cells were kindly provided by the Department of Parasitology, Institute of Biological Sciences, Federal University of Minas Gerais [30]. Briefly, the culture IDE8 tick cells were incubated in complete L15B culture medium (Sigma-Aldrich, Brazil), supplemented with $7 \%$ fetal bovine serum without antibiotics. The $A$. marginale UFMG 2 was inoculated in the IDE8 cell culture, incubated at $34{ }^{\circ} \mathrm{C}$ for 15 days and monitored by microscopy using Giemsa staining. Then, the infected IDE8 cells were detached by trypsinization and washed to remove traces of trypsin. For the $A$. marginale release, the IDE8 cells were ruptured by shearing using a sterile insulin-like syringe. Threeweek-old female BALB/c mice were divided into three groups. One group received three immunization series of the hybrid MSP1a/OMP7/9 protein mixed with the ISA adjuvant (immunized group; $N=5$ ). The second group $(N=5)$ received only the ISA adjuvant (adjuvant group), and the third group $(N=5)$ received PBS (non-immunized group; $N=5$ ). The mice were challenged with $3 \times 10^{5}$ cells $/ \mathrm{mL}$ of $A$. marginale UFMG2. All animals were monitored temperature and weight every day, fur alterations, as opacity and ruffle, and disturbed behavior, as aggressiveness or lethargy. The lethargy and weight loss were indicative of disease severity in the non-immunized mice. In the 42 day, adjuvant group presented high level of lethargy, then all animals were euthanized with an overdose of combining chemical anesthetics, as previously described [31].

\section{Selection of vaccine epitopes and protein construct}

To design the hybrid, MSP1a/OMP7/8/9 were selected, and $\mathrm{T}$ - and B-cell epitopes were predicted from the MSP1a tandem repeats and the common epitopes of Omp7, Omp8 and Omp9 according to the antigenicity, flexibility and immune dominancy using the Immune epitope algorithm [32]. The 3D prediction was analyzing by the i-TASSER algorithm [33]. The in silico-designed synthetic hybrid MSP1a/Omp7/8/9 gene was flanked with 6-histidine nucleotide codons at the amino-terminus for purification by affinity chromatography. Furthermore, the hybrid MSP1a/Omp7/8/9 gene was codon optimized for expression in the Escherichia coli strain DH $5 \alpha F^{\prime} I Q$ and was obtained as a synthetic DNA double strand from IDT (Integrated DNA Technologies, USA). The synthetic DNA was then cloned into pGEM-T Easy (Promega) and sub-cloned into pHT43 (Mo_Bi_Tec). A chemical transformation was performed using $\mathrm{CaCl}_{2}$ in E. coli DH $5 \alpha \mathrm{F}^{\prime} \mathrm{IQ}$, followed by incubation at $37^{\circ} \mathrm{C}$ for $1 \mathrm{~h}$, and raw MSP1a/OMP7/8/9 was obtained after culturing in isopropyl $\beta$-D-1-thiogalactopyranoside (IPTG) $1 \mathrm{mM}$, ampicillin, and an LB medium.

\section{Protein purification and vaccine formulation}

A 6x-histidine tag was added to the synthetic MSP1a/ omp7/8/9 protein at the amino-terminus, and the purification was performed using Nickel-labeled Sepharose affinity chromatography. Briefly, fifty milliliters of the bacterial growth of $E$. coli DH5 $\alpha F^{\prime} I Q$ transformed with pHT43-MSP1a/OMP7/9 were resuspended in MCAC buffer $(20 \mathrm{mM}$ Tris $\mathrm{pH} 7.9,0.5 \% \mathrm{w} / \mathrm{v} \mathrm{NaCl}$ and $10 \% \mathrm{v} / \mathrm{v}$ of glycerol). Twenty-five microliters of Triton-X100 were added to disrupt the membrane by freezing and thawing. After $10000 \times g$ spin for $20-30 \mathrm{~min}$ at $4{ }^{\circ} \mathrm{C}$, the supernatant was filtered through a $0.22 \mu \mathrm{m}$ membrane and purified with Ni-NTA superflow 6xHis tagged, according to protocol (Qiagen, Brazil). The purification was performed using an MCAC buffer adjusted to a $\mathrm{pH}$ of 8.0 for binding, $\mathrm{pH}$ of 6.0 for lavage and $\mathrm{pH}$ of 3.0 for elution. The MSP1a/OMP7/8/9 hybrid was emulsified in ISA adjuvant (MONTANIDE ${ }^{\mathrm{TM}}$ ISA $50 \mathrm{~V} 2$, Seppic, Brazil) with a final concentration of $0.144 \mu \mathrm{g} / \mathrm{mL}$ MSP1a/OMP7/8/9 in $22 \%$ aqueous and $78 \%$ oil ISA adjuvant. The aqueous-oil emulsion was prepared by shearing using sterile syringes connected by a silicone hose.

\section{Characterization and antigenicity of MSP1a/OMP7/8/9}

The molecular weight and purity of MSP1a/OMP7/8/9 were characterized on SDS-PAGE gel, and the antigenicity was evaluated by western blotting with bovine anaplasmosis serum. After running on the 15\% SDSPAGE gel, the proteins were transferred to a nitrocellulose membrane following the Bio-Rad protocol (Bio-rad, Brasil). Serum from a calf infected with $A$. marginale was obtained from a farm located in the city of Gurupi at coordinates $11^{\circ} 43^{\prime} 45^{\prime \prime} \mathrm{S}, 49^{\circ} 04^{\prime} 07^{\prime \prime} \mathrm{W}$ in the State of Tocantins, Brazil. Serum from healthy calves was employed as a negative control and used with peroxidase-conjugated rabbit IgG- anti-Bovine (Sigma, Brazil) at $1 / 2000$ and the $0.05 \%$ of the $3,3^{\prime}$-Diaminobenzidine substrate (DAB).

\section{Immunogenicity of the MSP1a/OMP7/8/9 recombinant}

Seven-week-old female BALB/c mice were used to assess the immunogenicity of our protein. Briefly, the mice were sedated according to our standards for the use of sedation in animals. Mice in the immunized group received MSP1a/OMP7/8/9 emulsified in ISA adjuvant, the adjuvant group received ISA $50 \mathrm{~V} 2$, and the non-immunized group received PBS. A volume of $100 \mu \mathrm{L}$ was administered intramuscularly at 0,21 , and 42 days. To evaluate and quantify the IgG anti-MSP1a/OMP7/8/9 antibody 
serum levels, $100 \mu \mathrm{L}$ of blood was collected after sedation and analgesia by check puncture on days 0,21 , and 42 . Sera from non-immunized mice were used to calculate a cut-off value for the ELISA.

\section{Enzyme linked immunosorbent assay (ELISA)}

Animals received three immunizations with 20 day intervals between doses, and the serum IgG was obtained before each immunization. In brief, $4 \mu \mathrm{g} / \mathrm{mL}$ of hybrid MSP1a/OMP7/8/9 were sensitized overnight at $4{ }^{\circ} \mathrm{C}$ in 96-well microplates (Nunc MaxiSorp ${ }^{\circledR}$ ). After blocking for $1 \mathrm{~h}$ with $2 \%$ casein-PBS buffer (blocking buffer) at room temperature, the plates were washed (4 times) with $0.05 \%$ Tween-20-PBS buffer. The serum was diluted at a ratio of 1:50 in the blocking buffer and incubated for $16 \mathrm{~h}$ at $4{ }^{\circ} \mathrm{C}$. After washing, the anti-mouse IgG peroxidase conjugate (Sigma, USA) was used at a dilution of 1:10 000 in the blocking buffer. After washing, TMB (BD Biosciences, USA) was added for $15 \mathrm{~min}$ and blocked with $2.5 \mathrm{M} \mathrm{H}_{2} \mathrm{SO}_{4}$. For immunogenicity evaluation, the optical density (OD) was measured at $450 \mathrm{~nm}$ and the reactivity of sera from non-immunized mice were used to determine the cut-off for anti MSP1a/OMP7/8/9. First, the mean was calculated with OD values of sera collected of each animal of three groups before to start the immunization $(N=15)$. The variance among the OD values was estimated by standard deviation (SD). The cut-off was determined by equation cut-off $=$ mean $\mathrm{OD}+2 \times \mathrm{SD}$. The values above the cutoff were considered positive.

\section{Hematological data, rickettsemia counts and quantification of spherocytes}

Forty-two days after the challenge, blood samples were obtained for the leukogram analysis at the Pet Shop Dog Center Veterinary Clinic (Gurupi/TO-Brazil). The nonimmunized mice were used as a reference for the leukogram data. The rickettsemia was counted by optical microscopy using Giemsa staining [12]. In addition to the rickettsemia, changes in the erythrocytes and impaired pigmentation (spherocytosis) were measured. The free A. marginale UFM2 was quantified by microscopy using Giemsa staining, and the challenge dose was established with $3 \times 10^{5}$ cells $/ \mathrm{mL}$.

\section{Histopathology}

The liver and spleen were removed by necropsy and were fixed in $10 \%$ buffered formalin for the histopathology analyses. The tissues were processed and embedded in paraffin, and each tissue was used for the H\&E staining. The liver and spleen lesions were evaluated based on histopathology observed during chronic A. marginale infection. The liver alteration were characterized by binucleation and hydropic degeneration in hepatocytes accompanied by inflammation, hyperemia, perivasculitis, and necrosis. In the spleen, lymphoid follicle atrophy associated with histiocytosis and fibrosis in both white and red pulps indicated anaplasmosis. Signs of immunization were evidenced by periarteriolar and follicular hyperplasia in the white pulp. Thus, each animal of the experimental groups received a score according to the grade of the alteration of liver and spleen as follows: (0) absence; (1) discrete, up to $25 \%$ of the field of observation; (2) moderate, greater than $25 \%$, but less than $50 \%$, of the field of observation; and (3) strong, greater than $50 \%$ of the field of observation.

\section{Statistical analysis}

The Kruskal-Wallis ANOVA test was used to compare the three groups (i.e., immunized, adjuvant and non-immunized mice). To test any overall differences between related means measure of body weight, mice were followed for 42 days post-infection, and compared by Repeated Measures ANOVA (RM-ANOVA). The survival percentage was calculated by Kaplan Meyer analysis. The following parameters were compared: the number of mice presenting symptoms, leukogram counts, and rickettsemia and spherocytes counts. For the histopathological data, we compared the means of the scores from the animals $(n=5)$ in each group as follows: non-immunized versus adjuvant and non-immunized versus immunized group. The IgG anti-MSP1a/ OMP7/8/9 serum levels of the immunized, adjuvant and non-immunized groups were measured and compared using two-way ANOVA. A $p$-value $<0.05$ with a $95 \%$ CI was considered significant.

\section{Results}

Structure, expression, antigenicity and immunogenicity of the hybrid MSP1a/OMP7/8/9

The MSP1a/OMP7/8/9 synthetic DNA sequence was designed with repeats in MSP1a and two common sequences from OMP7, OMP8 and OMP9 using A. marginale GenBank: JN564640.1 St. Maries. From MSP1a, we inserted STSSQLGGS $(n=2)$, STSSQL $(n=1)$ and one known sequence SEASTSSQLGA $(n=1)$ located between amino acids $15^{\circ}$ to $153^{\circ}$ of $m s p 1$ gene. We used two common sequences, GSSAVAAGFGGDDTDFYLGFG and EIPAVAANTFGANDVSTVNMGGLSPDI, from OMP7, OMP8 and OMP9 located at position 1-58 of omp7 gene (Figure 1A). The synthetic MSP1a/ OMP7/8/9 sequence was inserted into a 6-his-tag plasmid for purification. The 3D prediction suggested that the MSP1 repeats and common OMP7-OMP9 surface antigens were exposed on the surface of the hybrid protein (Figure 1B). In detail, the cloned motifs displayed tertiary conformations (Figure 1C). 


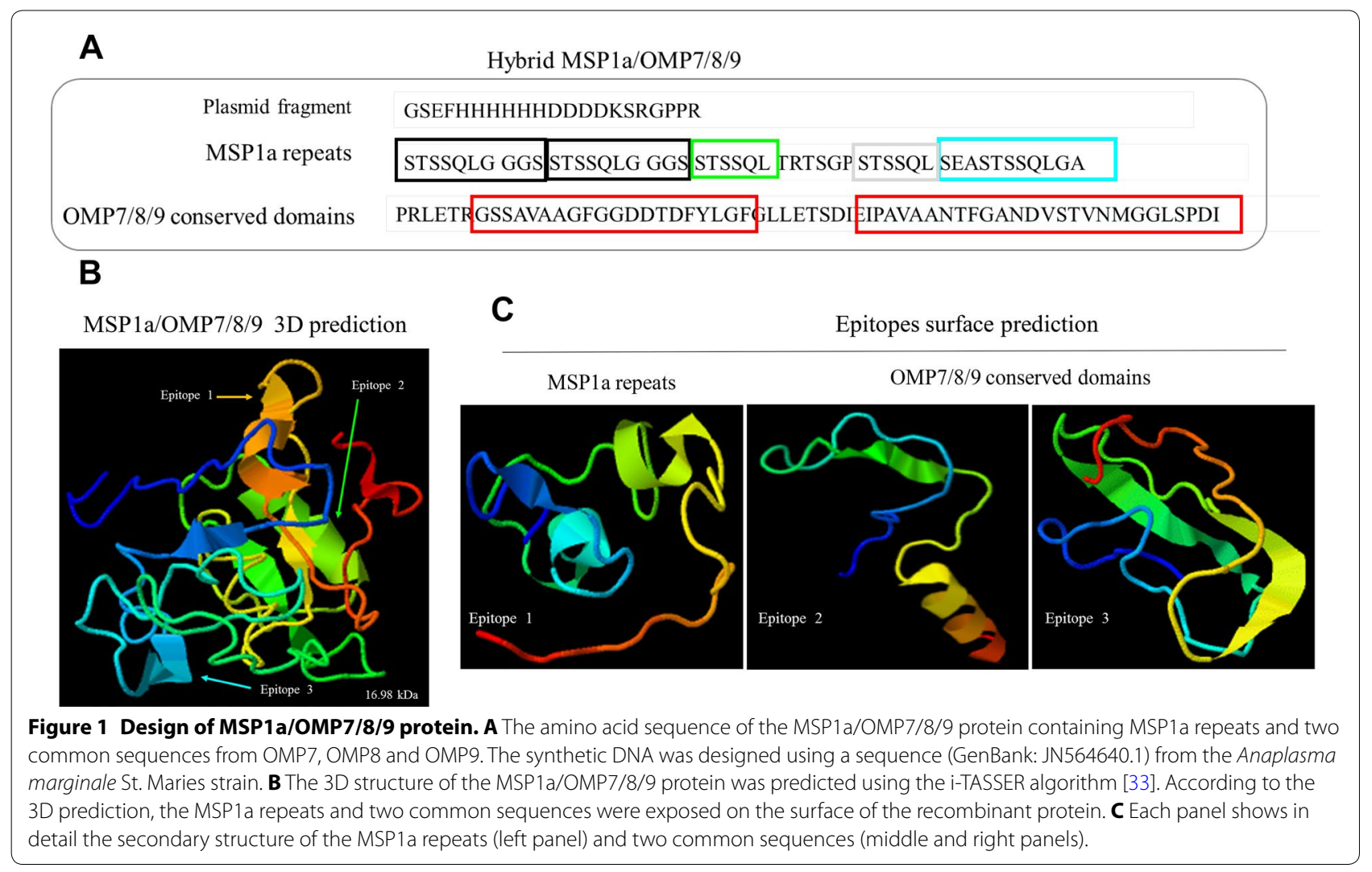

The in silico analysis suggested that the MSP1a/ OMP7/8/9 protein was $17 \mathrm{kDa}$ (ProtParam software), which was confirmed after its expression (Figure 2A) and purification on SDS/PAGE (Figure 2B). In addition, we confirmed that the purified protein was expressed as a hisTag by immunoblotting with an anti-hisTag antibody (Figure $2 \mathrm{C}$ ). Then, the immunoblotting and probing of serum from animals with anaplasmosis confirmed the MSP1a/OMP7/8/9 antigenicity in comparison to the healthy calf serum, which served as a negative control (Figure 2D). Furthermore, after immunizing the mice with three doses of the protein, the immunogenicity was confirmed by measuring the anti-MSP1a/OMP7/8/9 IgG antibodies by ELISA. The high antibody titers confirm the immunogenicity and suitability of this antigen as a vaccine candidate (Figure 2E).

\section{In vivo challenge with $A$. marginale in immunized mice}

Three groups of mice were challenged with $3 \times 10^{5}$ cells/ $\mathrm{mL}$ of $A$. marginale UFMG2a and were observed for 42 days for anaplasmosis symptoms, such as weight loss, lethargy, ruffled and/or opaque fur and death (Table 1). Lethargy and weight loss evidenced severity of disease in the non-immunized group. In the 42 day, adjuvant group presented lethargy, hence the survivors' animals were euthanized. The immunized group did not display any symptoms, while the subclinical dose was able to cause body weight loss in the non-immunized group after 30 day $(p<0.001)$, which coincided with the naturally occurrence of acute anaplasmosis (Figure 3A). Additionally, the overall coefficient of variation of the body weights of the immunized mice was low compared to that of the non-immunized group. The body weight loss in the adjuvant group was intermediary to both groups without a significant difference (data not shown). Nonetheless, ruffled and opaque fur was evident in the surviving mice in the non-immunized and adjuvant group (Table 1). The mice immunized with the hybrid MSP1a/ OMP7/8/9 protein showed better weight control and no clinical presentation of anaplasmosis compared with the non-immunized mice (Figure 3B).

At 42 day after the challenge, the rickettsemia and spherocytes were quantified using optical microscopy to detect cell free rickettsia and infected erythrocyte cells (Figures $3 \mathrm{C}$ and $\mathrm{D}$ ). The high intracellular invasion and cell destruction indicated rickettsia in the 


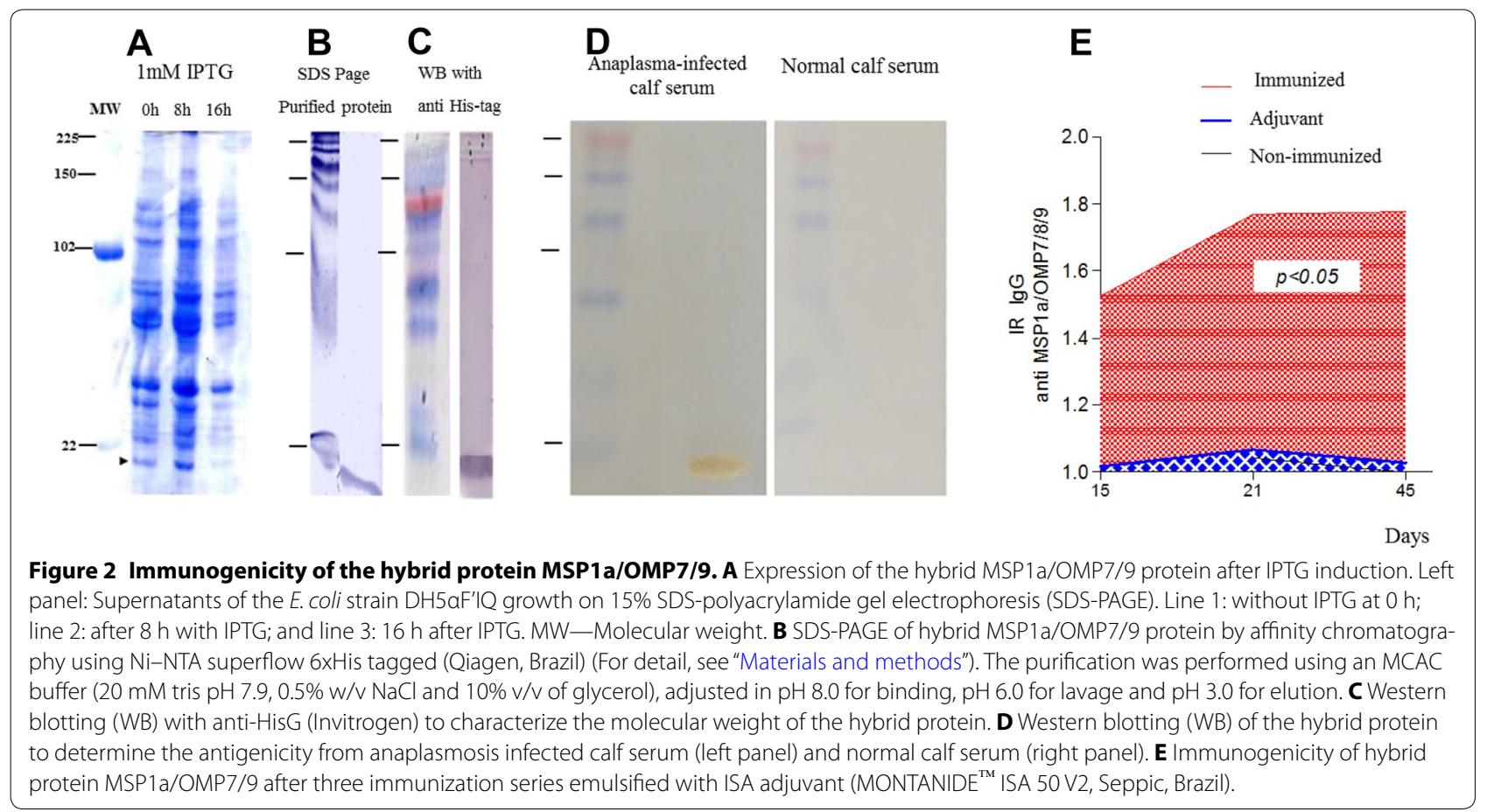

Table 1 Comparison between signals and leukogram data between MSP1a/OMP7/8/9 protein-immunized mice and controls mice

\begin{tabular}{|c|c|c|c|c|c|}
\hline & Immunized & Adjuvant & Non-immunized & $p$ & Reference \\
\hline \multicolumn{6}{|c|}{ Symptoms, animals with symptom (Total of animals) } \\
\hline Opaque fur & $0(5)$ & $5(5)$ & $5(5)$ & nd & $0(5)$ \\
\hline Ruffled fur & $0(5)$ & $5(5)$ & $5(5)$ & nd & $0(5)$ \\
\hline Weight loss & $0(5)$ & $0(5)$ & $5(5)$ & nd & $0(5)$ \\
\hline Lethargy & $0(5)$ & $5(5)$ & $5(5)$ & nd & $0(5)$ \\
\hline Death & $0(5)$ & $0(5)$ & $2(5)$ & nd & $0(5)$ \\
\hline \multicolumn{6}{|l|}{ Leukogram ${ }^{b}$} \\
\hline Leucocytes & $5600.0(529.2)^{*}$ & $7266.7(1814.8)$ & $7733.3(1222.0)^{*}$ & 0.0415 & $3483.3(2119.7)$ \\
\hline Lymphocytes & $2053.5(835.3)$ & $2640.0(254.4)$ & $2242.7(671.0)$ & 0.3967 & $2223.4(778.2)$ \\
\hline Monocytes & $130.0(29.5)^{*}$ & $180.7(112.9)$ & $253.3(12.2)^{*}$ & 0.0071 & $210.7(27.2)$ \\
\hline Neutrophils & $3318.7(370.1)^{*}$ & $4457.3(1411.7)$ & $5104.0(595.9)^{*}$ & 0.0380 & $2014.0(1396.4)$ \\
\hline Red cells, millions $/ \mathrm{mm}^{3}$ & $5.6(0.5)$ & $5.5(0.9)$ & $6.4(0.6)$ & 0.0631 & $5.6(0.6)$ \\
\hline Hemoglobin g/dL & $16.8(1.4)$ & $16.7(2.8)$ & $19.5(1.9)$ & 0.1324 & $16.9(1.8)$ \\
\hline Hematocrit \% & $50.3(4.0)$ & $50.3(8.3)$ & $58.7(5.8)$ & 0.1303 & $50.7(5.5)$ \\
\hline $\mathrm{MCV} / \mathrm{mm}^{3}$ & $90.3(0.6)$ & $90.7(0.6)$ & $91.0(0.0)$ & 0.2605 & $90.3(0.6)$ \\
\hline $\mathrm{MHV} / \mathrm{mm}^{3}$ & $30.0(0.0)$ & $30.0(0.0)$ & $30.0(0.0)$ & 0.9999 & $30.0(0.0)$ \\
\hline $\mathrm{MCHC} / \mathrm{mm}^{3}$ & $33.0(0.0)$ & $33.0(0.0)$ & $33.0(0.0)$ & 0.9999 & $33.0(0.0)$ \\
\hline Platelets, millions $/ \mathrm{mm}^{3}$ & $323.7(97.0)$ & $403.3(139.5)$ & $281.3(138.6)$ & 0.6447 & 309.7 (45.6) \\
\hline Creatinine, mg/dL & $1.2(0.5)$ & $1.2(0.4)$ & $1.2(0.5)$ & 0.9854 & $1.1(0.5)$ \\
\hline Urea, mg/dL & $56.3(33.6)$ & $55.0(8.9)$ & $52.0(18.5)$ & 0.9999 & $61.3(20.4)$ \\
\hline
\end{tabular}

nd: not done.

* significance found by Kruskal Wallis T-test.

a Animals with symptom (Total of animals).

b For leukogram data, only three animals have been used in each parameter. Mean (standard deviation). 

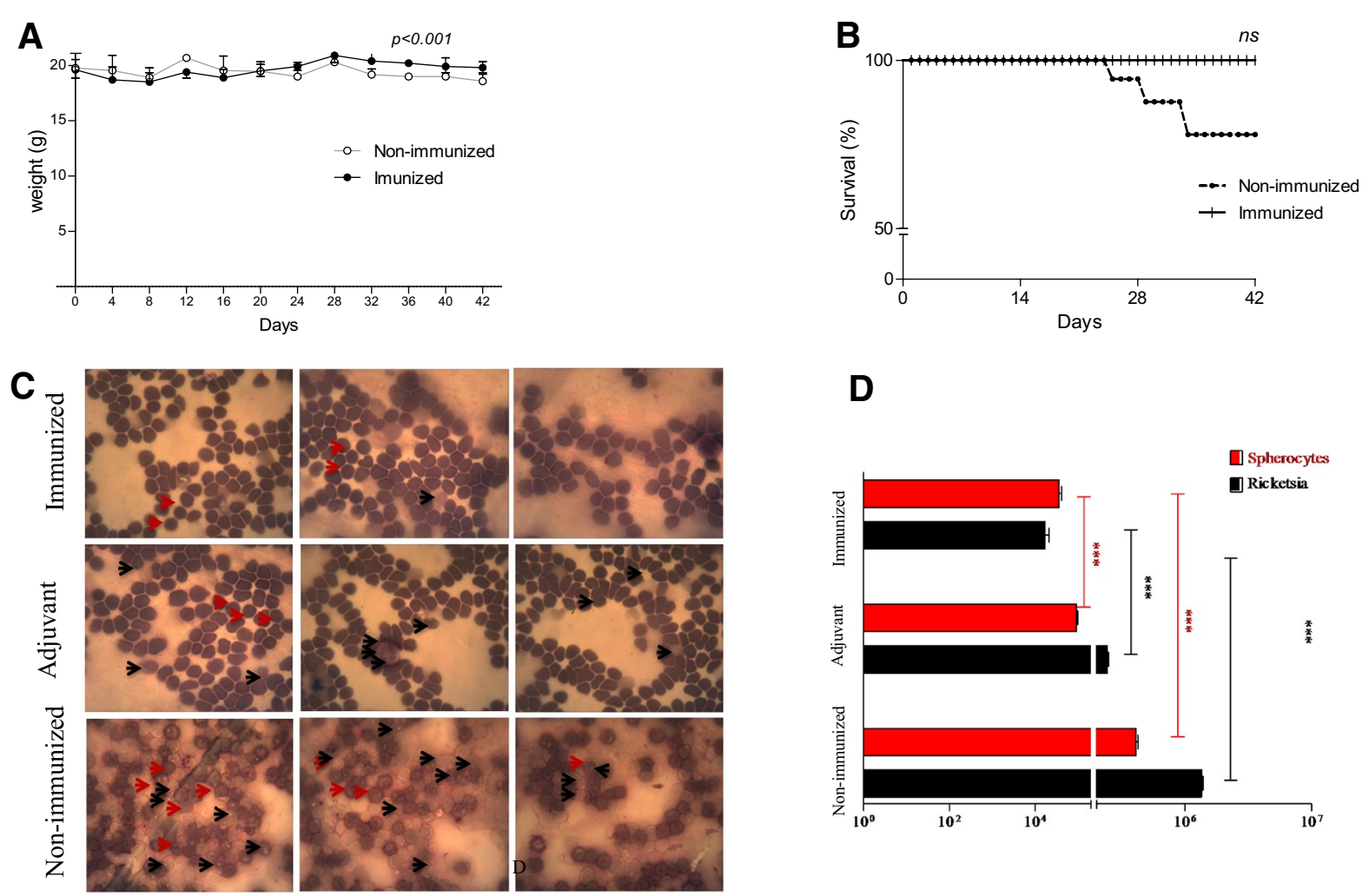

D

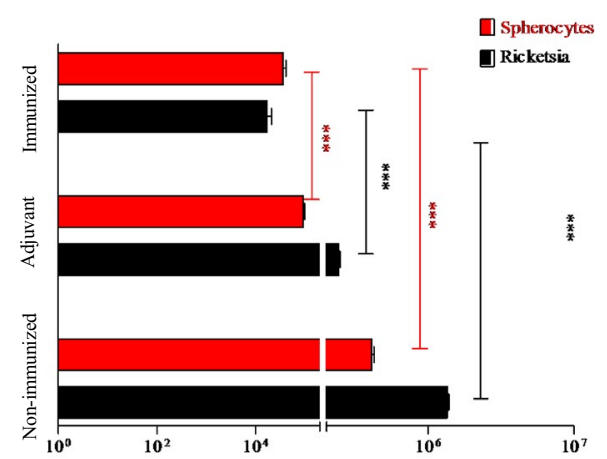

Figure 3 Challenge with the $\boldsymbol{A}$. marginale strain UFMG2 in mice. Three-week-old female BALB/c mice were divided into three groups. One group received three immunization series of the hybrid MSP1a/OMP7/9 protein mixed with the ISA adjuvant (immunized group; $N=5$ ). The second group $(N=5)$ received only the ISA adjuvant (Adjuvant group), and the third group $(N=5)$ received PBS (non-immunized group; $N=5$ ). The mice were challenged with $3 \times 10^{5}$ cells $/ \mathrm{mL}$ of $A$. marginale UFMG2. The animals were observed for 42 days to measure weight loss, deaths, and signs, such as lethargy and ruffled and opaque fur (see Table 1). A Differences between related means of body weight followed for 42 days post-infection, the RM-ANOVA Test showed differences between the immunized and non-immunized mice showed differences between the immunized and non-immunized mice. The difference was evaluated by two-way RM ANOVA. The adjuvant group did not differ from either group (not shown). B The immunized group had $100 \%$ survival while $60 \%$ of non-immunized mice survived in Kaplan Meyer analysis. The adjuvant group did not differ from the immunized mice (not showing). C Morphological changes, such as cell destruction and pigmentation loss and featuring bacterial invasion in infected erythrocytes at 48 days post-infection. D Rickettsemia and A. marginale load and spherocytes counts were determined with blood smears stained with hematoxylin-eosin by optical microscopy [10].

non-immunized group (Figure 3C). In addition, we observed a 100 -fold increase in the rickettsemia in the non-immunized group compared to the immunized group (Figure 3D).

The rickettsemia was significantly lower in the immunized group than that in the adjuvant group $(p<0.001)$, while that the rickettsemia observed in the adjuvant group also was different compared to the non-immunized mice (Figure 3D). The morphological changes in the infected erythrocytes were compared, and the immunized group had a fewer number of spherocytes that the adjuvant and non-immunized group $(p<0.0001)$. In summary, the immunized mice exhibited a control of the A. marginale infection at subclinical levels and were protected against anaplasmosis.

\section{Hematological and histopathological presentation in the control and immunized mice}

To assess with the effects of an A. marginale infection in mice, we performed complete blood counts and assessed the morphological alterations in the spleen and liver 42 day after the challenge. The immunized mice had moderate leukocytosis $(5600 \pm 529 ; p<0.05)$. No significant difference in the number of lymphocytes was observed among the three experimental groups. However, increases in the neutrophils were observed in the non-immunized and adjuvant group compared to immunized group. The immunized group had lower monocyte counts after the $A$. marginale infection while weight loss, lethargy, ruffled and/or opaque fur and death were observed in the non-immunized and adjuvant group (Table 1). Overall, neutrophils and monocytes 
participated in the disease pathology and were important in protecting the mice against anaplasmosis.

To assess the mechanism by which the hybrid MSP1a/ OMP7/8/9 protein provided protection in the immunized mice, we performed a pathological analysis of the liver and spleen. A summary of the histopathological analysis of the liver and spleen scored by comparing to the uninfected mice is provided in Table 2. The infection caused binucleated hepatocytes in the three groups, however non-immunized group displayed intense areas associated with perivasculitis, hyperemia and necrosis
(Figure 4A). The binucleated hepatocytes areas in adjuvant group were more numerous than in immunized group. Nonetheless, the scores did not differ statistically. Another histopathological manifestation, the hydropic degeneration occurred only in the non-immunized group. The hydropic degeneration was well defined as cells without cytoplasm organization by central zones of the hepatic lobules. In the immunized mice, the hydropic degeneration score was minimal, while was intermediate in the adjuvant group. In the spleen, only the immunized group showed significant stimuli in the white pulp, and

Table 2 Histological changes in the spleen of MSP1a/OMP7/8/9 protein-immunized mice and controls mice

\begin{tabular}{|c|c|c|c|c|c|c|c|c|}
\hline & \multicolumn{2}{|l|}{ LIVER } & \multicolumn{6}{|l|}{ SPLEEN } \\
\hline & \multicolumn{2}{|c|}{$\begin{array}{l}\text { Hydrotropic degenera- } \\
\text { tion }\end{array}$} & \multicolumn{2}{|c|}{ White pulp hyperplasia } & \multicolumn{2}{|c|}{ Periarteriolar hyperplasia } & \multicolumn{2}{|c|}{ Follicular hyperplasia } \\
\hline & $95 \% \mathrm{Cl}$ & $p$ & $95 \% \mathrm{Cl}$ & $p$ & $95 \% \mathrm{Cl}$ & $p$ & $95 \% \mathrm{Cl}$ & $p$ \\
\hline Non-immunized vs. immunized & 0.2695 to 1.731 & $* *$ & -2.397 to -0.9361 & $* *$ & -2.064 to -0.6028 & $* *$ & -2.397 to -0.9361 & ** \\
\hline Non-immunized vs. adjuvant & -0.7305 to 0.7305 & ns & -0.7305 to 0.7305 & ns & -0.7305 to 0.7305 & ns & -1.397 to 0.06387 & ns \\
\hline
\end{tabular}

ns: not significant.

** $p<0.005$.
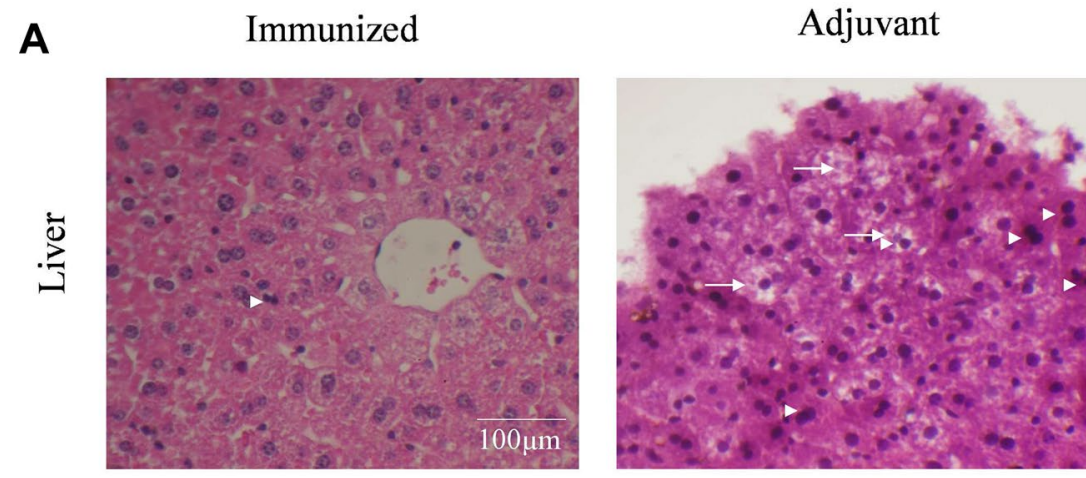

\section{Non-immunized}
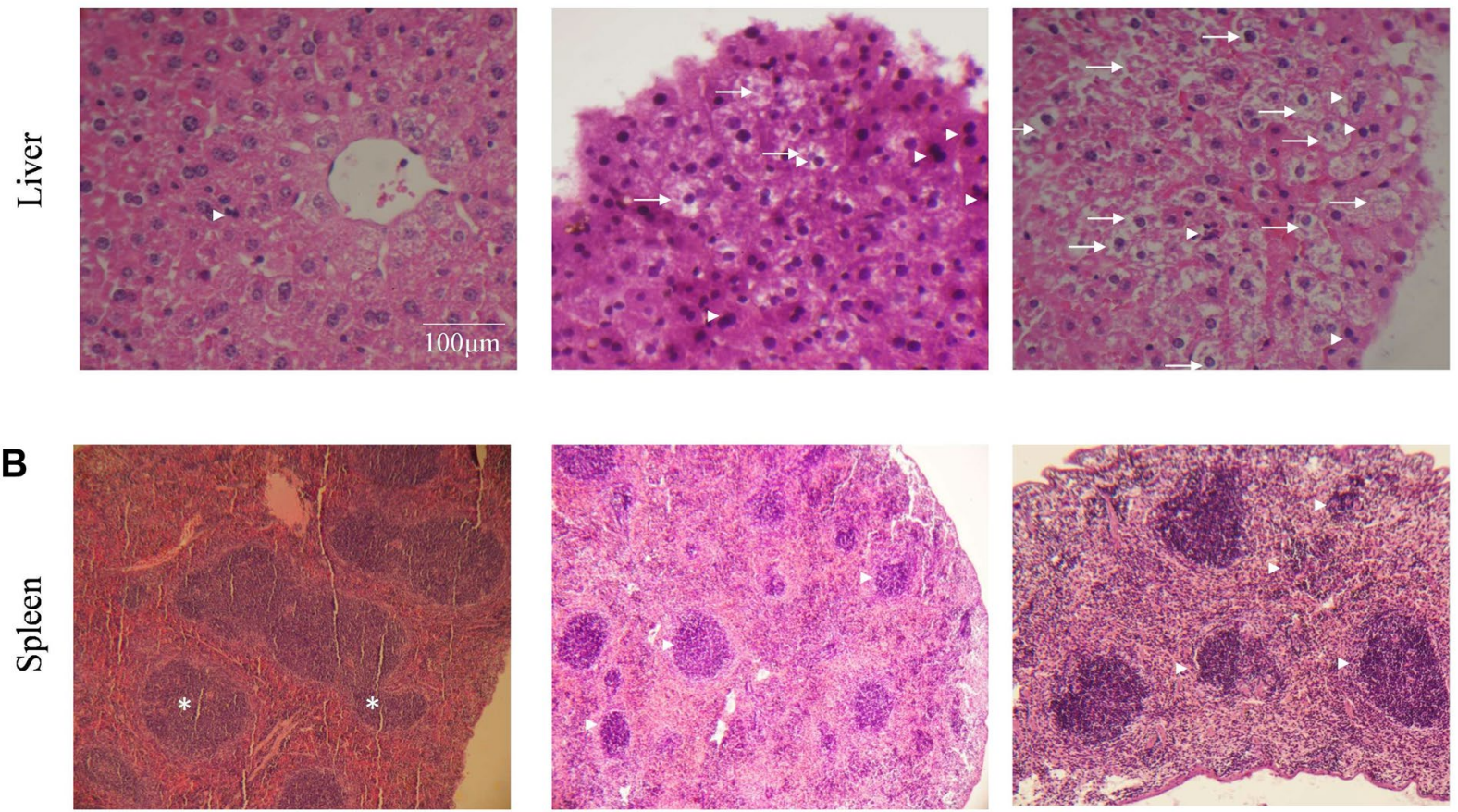

Figure 4 Liver and spleen modifications after the A. marginale challenge. All groups were challenged with $3 \times 10^{5}$ cells $/ \mathrm{mL}$ A. marginale UFMG2. A The liver histopathology shows hepatocytes binucleation (arrow head) and hydropic degeneration (arrow). B The spleen analysis indicates follicular hyperplasia in the white pulp (asterisk). In contrast, the adjuvant and non-immunized group showed lymphoid follicle atrophies (arrow head). Hematoxylin and eosin staining and scale bar $=100 \mu \mathrm{m}$. 
periarteriolar and follicular hyperplasia was well defined (Table 2). The white pulp and follicular area expansions demonstrate a consequence of the antigenic stimulation and subsequent proliferation of B cells (Figure 4B). These modifications were not present in the control and adjuvant group, implicating lymphoid follicle atrophies.

\section{Discussion}

Although vaccination is the best strategy against anaplasmosis, the high production cost, rickettsial genetic diversity, and risk associated with live vaccines impose great difficulties on anaplasmosis control $[1,25,35,36]$. Thus, new strategies are needed for rationale vaccine development. The genus Anaplasma, belonging to order Rickettsiales, comprise species that are causative of tick-borne diseases and have a remarkable impact on human and animal health $[1,35,37]$. Previously, the major pitfall in anaplasmosis research was the lack of a suitable small animal model. However, several recent studies have demonstrated that the histopathological changes associated with acute and chronic $A$. marginale infections can be reproduced in murine models [26, 27, 38, 39].

Here, we have also successfully infected BALB/c mice with A. marginale UFMG2 released from IDE8 after mechanic rupture. Lethargy and weight loss evidenced severity of disease in mice non immunized and in mice of adjuvant groups with lethargy at 42 days after infection. We also evaluated hematological status and manifestations of disease in liver and spleen by histopathology examination.

Despite the use of a subclinical dose, the non-immunized mice developed liver lesions and displayed increases in the WBC, neutrophil and monocyte counts. With persistent infection, these mice displayed spherocytes as a consequence of infected erythrocytes and hepatic lesions, which is similar to the murine model of human granulocytic anaplasmosis [27, 29]. It has been established that neutrophils could be important mediators of innate responses, but under aberrant activation, they cause inflammatory hepatic lesions $[10,40,41]$. Consistently, the non-immunized group displayed increases in the neutrophil counts during the chronic infection that were concomitant with an intense hydropic degeneration throughout the hepatic portal and central zones [29]. Moreover, these mice displayed intense areas with binucleated hepatocytes associated with perivasculitis, hyperemia and necrosis, as observed in classical anaplasmosis models $[10,42]$. Adjuvant group displayed slight histopathological manifestations. Hydropic degeneration occurred exclusively in these mice, which is consistent with several of the hepatic lesions observed in murine models of human monocytic ehrlichiosis [41]. Despite a subclinical dose with the highly fatal $A$. marginale strain, no liver lesions or changes were observed in the WBC count of immunized mice. These findings indicated conferred protection against anaplasmosis after immunization with hybrid protein. In contrast, the spleen from the non-immunized group displayed a discrete splenomegaly with few inflammatory infiltrates and focused follicular atrophy in the white pulp, which is a characteristic of spleen histopathology that is common in calves [10, 29, 43]. However, our immunized group displayed hyperplasia in the white pulp characterized by increased cellularity of larger, rounded and regular nuclear membranes and even paler stained cells, which is suggestive of a response to antigenic stimuli $[43,44]$.

Evidence has shown that the MSP-1 complex and both MSP-la and MSP-lb individually mediate adherence to bovine erythrocytes, and the antibody response against these proteins could block parasite invasion of erythrocytes and disease spread [1,37, 45-47]. However, antigenic variability has hampered $A$. marginale vaccine development, whereas immunization with single antigens has shown partial or little protection against an $A$. marginale challenge $[1,12,48,49]$. In this study, we have overcome this problem by creating a hybrid protein with immunodominant epitopes of several important surface protein; in addition, we also considered the antigenic variability for an efficient immune response [12, 18, 26, $46,47,50,51]$. Our hybrid protein contained motifs of a single MSP1a from the most characterized protein of the A. marginale MSPs [15] and three little-known OMP7-9 located in a putative operon from the $m s p 2$ superfamily [22]. We designed, in tandem, longer sequences of the MSP1a repeats (STSSQLGGS and SEASTSSQLGA) with two common sequences of OMP7, OMP8 and OMP9 (GSSAVAAGFGGDDTDFYLGFG and EIPAVAANTFGANDVSTVNMGGLSPDI), and identified invariant and potential vaccine candidates that are highly expressed in bovine $A$. marginale-infected erythrocytes $[14,18,20,22$, $25,26,35,52]$. The $3 \mathrm{D}$ prediction analysis suggested that our design allowed for the exposition of these motifs on the recombinant protein surface.

In the present study, our proof-of-concept was that a hybrid protein containing several epitopes of different antigens could protect mice against a challenge with a live and highly virulent $A$. marginale strain (UFMG2) [26, 34]. The immunized BALB/c mice did not exhibit signs of anaplasmosis, and the survival rate was $100 \%$, while the non-immunized and adjuvant groups presented ruffled and opaque fur and considerable weight losses after the challenge. The serological responses after the immunization showed a considerably higher immunogenicity for MSP1a/OMP7/8/9, indicating that the protection against anaplasmosis may be associated with the elicitation of effector functions of humoral and cellular immune 
responses [18, 26]. Microscopically, we also demonstrated, for the first time, that the immunized group did not present damage in the red blood cells nor hepatic lesions. Thus, the prominent germinal centers in the secondary follicles in the immunized mice indicated that our hybrid protein elicited an effector humoral response that allowed us to evaluate the protection against $A$. marginale $[18,26,47,53]$.

In summary, we demonstrated a useful murine model to study $A$. marginale infection and design a recombinant protein containing potential epitopes of different antigens. Our hybrid protein immunization induced a strong reduction in rickettsemia and conferred protection against anaplasmosis. Thus, we provided strong protection against anaplasmosis with a hybrid protein, and therefore, other hybrid proteins should cover the antigenic diversity of $A$. marginale to achieve candidate subunit for anaplasmosis vaccine.

\begin{abstract}
Abbreviations
COBEA: Brazilian College of Animal Experimentation; A. marginale UFM2: virulent strain of cattle isolated by Prof. Dr. Mucio Ribeiro of the Federal University of Minas Gerais (UFMG strain number 2); IDE8: cell lines cell line Ixodes scapularis; RM ANOVA: repeated measures ANOVA; ISA: adjuvants for Water-in-Oil (W/O) MONTANIDE SEPPIC ISA 50 V2; MSP2: major surface protein 2; MSP1a: major surface protein 1a; OMP7/8/9: outer membrane protein 7,8 and 9 .
\end{abstract}

\section{Competing interests}

The authors declare that they have no competing interests.

\section{Authors' contributions}

ASRC and PAN analysed data and wrote the manuscript. LAMM, KDESP, SAF and PPO participated in the design and of the hybrid protein construction (MSP1a/OMP7/8/9). SE, HMS and CRFM analysed the histopathology data and manuscript revision. ASRC and KFV designed and carried out the animal experiments. MFBR: helped in all assistance with virulent strain $A$. marginale UFMG2 used in this work. PL: revision of the manuscript for English language and technical aspects of the work. All authors read and approved the final manuscript.

\section{Acknowledgements}

We acknowledge Prof. Dr. Mucio's team at the Laboratory of Parasitology Protozoology Department of Veterinary Institute of Biological Sciences, Federal University of Minas Gerais_UFMG for giving all assistance with virulent strain Anaplasma marginale UFMG2 used in this work. We acknowledge the technical assistance of Marisa Pardal in histological preparations. We acknowledge Antonio Balieiro from Instituto de Pesquisas Leônidas e Maria Deane (FIOCRUZ Manaus) for their statistics support.

\section{Ethics approval and consent to participate}

All experiments were performed in accordance with the ethical guidelines for experiments with mice, and the protocols were approved by the National Council for Control of Animal Experimentation, Federal University of Tocantins Animal Experimentation Committee (CEUA No 23101.003595/2015-15). The guidelines for animal use and care were based on the standards established by The Brazilian College of Animal Experimentation (COBEA).

\section{Funding}

This study has no granted, and it was performed with help of authors. We had not financial support to provide this study, but we acknowledge the FAPEAM for Keila Pereira's fellowship through the Graduate Biotechnology Program.

\section{Author details}

${ }^{1}$ Universidade Federal do Amazonas-Programa de pós-graduação em Rede de Biodiversidade e Biotecnologia da Amazônia Legal, Manaus, AM/Brasil, Brazil. ${ }^{2}$ Universidade Federal do Tocantins-Engenharia de Bioprocessos e Biotecnologia, Gurupi, TO/Brazil, Brazil. ${ }^{3}$ Instituto Leônidas e Maria Deane-Fiocruz Amazônia, Manaus, Amazonas/Brazil, Brazil. ${ }^{4}$ Departamento de Análises Clínicas e Toxicológicas da Faculdade de Ciências Farmacêuticas, Universidade de São Paulo, São Paulo, São Paulo/Brazil, Brazil. ${ }^{5}$ Departamento de Parasitologia do Instituto de Ciências Biológicas, Universidade Federal de Minas Gerais, Belo Horizonte, Minas Gerais/Brazil, Brazil. ${ }^{6}$ Faculdade de Medicina, Centro Universitário Unirg, Gurupi, Tocantins/Brazil, Brazil. ${ }^{7}$ Departamento de Parasitologia do Instituto de Ciências Biomédicas, Universidade de São Paulo, São Paulo, Brazil.

\section{Publisher's Note}

Springer Nature remains neutral with regard to jurisdictional claims in published maps and institutional affiliations.

Received: 13 November 2017 Accepted: 20 December 2017

Published online: 19 January 2018

References

1. Kocan KM, De Fuente J, Alberto A, Meléndez RD, Fuente D, Guglielmone A, Mele RD (2003) Antigens and alternatives for control of Anaplasma marginale infection in cattle. Clin Microbiol Rev 16:698-712

2. Kocan KM, De Fuente J, Blouin EF, Coetzee JF, Erwing SA (2010) The natural history of Anaplasma marginale. Vet Parasitol 167:95-107

3. Kuttler K (1984) Anaplasma infections in wild and domestic ruminants: a review. J Wildl Dis 20:12-20

4. Aubry P, Geale DW (2011) A review of bovine anaplasmosis. Transbound Emerg Dis 58:1-30

5. De Vos A, Brock R, Molly J (2006) Tick borne diseases of cattle. In: Australian and New Zealand Standard Diagnostic Procedures. Sub Committee on Animal Health Laboratory Standards pp 1-29

6. Woldehiwet Z (2010) The natural history of Anaplasma phagocytophilum. Vet Parasitol 167:108-122

7. Palmer GH, Rurangirwa FR, Kocan KM, Brown WC (1999) Molecular basis for vaccine development against the ehrlichial pathogen Anaplasma marginale. Parasitol Today 15:281-286

8. Richey EJ, Palmer GH (1990) Bovine anaplasmosis. Compend Contin Educ Pract Vet 12:1661-1668

9. Ben Said M, Belkahia H, Alberti A, Zobba R, Bousrih M, Yahiaoui M, Daaloul-Jedidi M, Mamlouk A, Gharbi M, Messadi L (2015) Molecular survey of Anaplasma species in small ruminants reveals the presence of novel strains closely related to A. phagocytophilum in Tunisia. Vector Borne Zoonotic Dis 15:580-590

10. Jaswal H, Bal M, Singla L, Gupta K, Brar A (2015) Pathological observations on clinical Anaplasma marginale infection in cattle. J Parasit Dis 39:495-498

11. Maharana BR, Tewari AK, Saravanan BC, Sudhakar NR (2016) Important hemoprotozoan diseases of livestock: challenges in current diagnostics and therapeutics: an update. Vet World 9:487-495

12. Ducken DR, Brown WC, Alperin DC, Brayton KA, Reif KE, Turse JE, Palmer GH, Noh SM (2015) Subdominant outer membrane antigens in Anaplasma marginale: conservation, antigenicity, and protective capacity using recombinant protein. PLoS One 10:e0129309

13. Michelon A, Conceição FR, Binsfeld PC, da Cunha CW, Moreira AN, Argondizzo AP, Mclntosh D, Armôa GRG, Campos AS, Farber M, McFadden J, Dellagostin OA (2006) Immunogenicity of Mycobacterium bovis BCG expressing Anaplasma marginale MSP1a antigen. Vaccine 24:6332-6339

14. Noh SM, Brayton KA, Brown WC, Norimine J, Munske GR, Davit CM, Palmer $\mathrm{GH}$ (2008) Composition of the surface proteome of Anaplasma marginale and its role in protective immunity induced by outer membrane immunization. Infect Immun 76:2219-2226

15. Palmer GH, McElwain TF (1994) Molecular basis for vaccine development against anaplasmosis and babesiosis. Vet Parasitol 57:233-253

16. Albarrak SM, Brown WC, Noh SM, Reif KE, Scoles GA, Turse JE, Norimine J, Ueti MW, Palmer GH (2012) Subdominant antigens in bacterial vaccines: 
AM779 is subdominant in the Anaplasma marginale outer membrane vaccine but does not associate with protective immunity. PLoS One 7:e46372

17. Dark MJ, Al-khedery B, Barbet AF (2011) Multistrain genome analysis identifies candidate vaccine antigens of Anaplasma marginale. Vaccine 29:4923-4932

18. Silvestre BT, Rabelo EML, Versiani AF, Da Fonseca FG, Silveira JAG, Bueno LL, Fujiwara RT, Ribeiro MFB (2014) Evaluation of humoral and cellular immune response of $B A L B / c$ mice immunized with a recombinant fragment of MSP1a from Anaplasma marginale using carbon nanotubes as a carrier molecule. Vaccine 32:14-17

19. Tebele N, McGuire TC, Palmer GH (1991) Palmer, induction of protective immunity by using Anaplasma marginale initial body membranes. Infect Immun 59:3199-3204

20. Crosby FL, Brayton KA, Magunda F, Munderloh UG, Kelley KL, Barbet AF (2015) Reduced infectivity in cattle for an outer membrane protein mutant of Anaplasma marginale. Appl Environ Microbiol 81:2206-2214

21. Lopez JE, Siems WF, Palmer GH, Brayton KA, McGuire TC, Norimine J, Brown WC (2005) Identification of novel antigenic proteins in a complex Anaplasma marginale outer membrane immunogen by mass spectrometry and genomic mapping. Infect Immun 73:8109-8118

22. Brayton KA, Kappmeyer LS, Herndon DR, Dark MJ, Tibbals DL, Palmer GH, McGuire TC, Knowles DP (2005) Complete genome sequencing of Anaplasma marginale reveals that the surface is skewed to two superfamilies of outer membrane proteins. Proc Natl Acad Sci U S A 102:844-849

23. Palmer GH, Brown W, Noh SM, Brayton KA (2012) Genome-wide screening and identification of antigens for rickettsial vaccine development. FEMS Immunol Med Microbiol 64:115-119

24. Herbert K, Seidman D, Oki A, Izac J, Emani S, Oliver LJ, Miller D, Tegels B, Kannagi R, Marconi R, Carlyon J (2017) Anaplasma marginale outer membrane protein $\mathrm{A}$ is an adhesin that recognizes sialylated and fucosylated glycans and functionally depends on an essential binding domain. Infect Immun 85:e00968-01016

25. Quiroz-castañeda RE, Amaro-Estrada I, Rodríguez-Camarillo SD (2016) Anaplasma marginale: diversity, virulence, and vaccine landscape through a genomics approach. Biomed Res Int 2016:9032085

26. Santos PS, Sena AAS, Nascimento R, Araújo TG, Mendes MM, Martins JRS, Mineo TWPJR, Goulart LR (2013) Epitope-based vaccines with the Anaplasma marginale MSP1 a functional motif induce a balanced humoral and cellular immune response in mice. PLoS One 8:e60311

27. Blas-Machado U, De Fuente J, Blouin EF, Almazán C, Kocan KM, Mysore JV (2007) Experimental infection of $\mathrm{C} 3 \mathrm{H} / \mathrm{HeJ}$ mice with the NY18 isolate of Anaplasma phagocytophilum. Vet Pathol 44:64-73

28. Borjesson DL, Barthold SW (2002) The mouse as a model for investigation of human granulocytic ehrlichiosis: current knowledge and future directions. Comp Med 52:403-413

29. Bunnel JE, Trigiani ER, Srinivas SR, Dumler JS (1999) Development and distribution of pathologic lesions are related to immune status and tissue deposition of human granulocytic ehrlichiosis agent-infected cells in a murine model system. J Infect Dis 180:546-550

30. Yang Q, Ghose P, Ismail N (2013) Neutrophils mediate immunopathology and negatively regulate protective immune responses during fatal bacterial infection-induced toxic shock. Infect Immun 81:1751-1763

31. Ortolan LS, Sercundes MK, Barbosa R, Debone D, Murilo O, Hagen SCF, Russo M, D'Imperio Lima MR, Alvarez JM, Amaku M, Marinho CRF, Epiphanio S (2014) Predictive criteria to study the pathogenesis of malaria-associated ALI/ARDS in mice. Mediators Inflamm 2014:872464

32. Zhang Q, Wang P, Kim Y, Haste-Andersen P, Beaver J, Bourne PE, Bui HH, Buus S, Frankild S, Greenbaum J, Lund O, Lundegaard C, Nielsen M, Ponomarenko J, Sette A, Zhu Z, Peters B (2008) Immune epitope database analysis resource (IEDB-AR). Nucleic Acids Res 36:W513-518

33. Zhang Y (2008) I-TASSER server for protein 3D structure prediction. BMC Bioinform 9:40

34. Bastos C, Passos P, Facury-Filho E, Rabelo E, De Fuente J, Ribeiro MFB (2010) Protection in the absence of exclusion between two Brazilian isolates of Anaplasma marginale in experimentally infected calves. Vet J 186:374-378

35. Chalovich JM, Eisenberg E (2012) Genome-wide screening and identification of antigens for rickettsial vaccine development. FEMS Immunol Med Microbiol 61:115-119

36. Wallace J, Hollis L, Reinhardt Coetzee J, Renter LD (2007) Failure to eliminate the Anaplasma marginale carrier state in beef cows following multiple treatments with long-acting injectable oxytetracycline. Bov Pract 41:84-87

37. Battilani M, De Arcangeli S, Balboni A, Dondi F (2017) Genetic diversity and molecular epidemiology of Anaplasma. Infect Genet Evol 49:195-211

38. Hodzic E, Feng S, Fish D, Leutenegger C, Freet K, Barthold S (2001) Infection of mice with the agent of human granulocytic ehrlichiosis after different routes of inoculation. J Infect Dis 183:1781-1786

39. Martink M, Bunnell J, Dumler J (2000) Pathology, immunohistology, and cytokine responses in early phases of human granulocytic ehrlichiosis in a murine model. J Infect Dis 181:374-378

40. MacNamara KC, Racine R, Chatterjee M, Borjesson D, Winslow GM (2009) Diminished hematopoietic activity associated with alterations in innate and adaptive immunity in a mouse model of human monocytic ehrlichiosis. Infect Immun 77:4061-4069

41. Scorpio DG, Von Loewenich FD, Göbel H, Bogdan C, Dumler JS (2006) Innate immune response to Anaplasma phagocytophilum contributes to hepatic injury. Clin Vaccine Immunol 13:806-809

42. Pagliari C, Quaresma JAS, Kanashiro-Galo L, De Carvalho LV, Vitoria WO, Da Silva WLF, Penny R, Vasconcelos BCB, Da Costa Vasconcelos PF, Duarte MIS (2016) Human kidney damage in fatal dengue hemorrhagic fever results of glomeruli injury mainly induced by IL 17. J Clin Virol 75:16-20

43. Suttie A (2006) Histopathology of the spleen. Toxicol Pathol 34:466-503

44. Elmore S (2006) Enhanced histopathology of the spleen. Toxicol Pathol 34:648-655

45. Brown WC, Shkap V, Zhu D, Mcguire TC, Tuo W, McElwain TF, Palmer GH (1998) CD4+ T-lymphocyte and immunoglobulin G2 responses in calves immunized with Anaplasma marginale outer membranes and protected against homologous challenge. Infect Immun 66:5406-5413

46. McGarey DJ, Allred DR (1994) Characterization of hemagglutinating components on the Anaplasma marginale initial body surface and identification of possible adhesins. Infect Immun 62:4587-4593

47. Tamekuni K, Kano FS, Ataliba AC, Marana ERM, Venâncio EJ, Vidotto MC, Garcia JL, Headley SA, Vidotto O (2009) Cloning, expression, and characterization of the MSP1a and MSP1b recombinant proteins from PR1 Anaplasma marginale strain, Brazil. Res Vet Sci 86:98-107

48. Han S, Norimine J, Palmer GH, Mwang W, Lahmers KK, Brown WC (2008) Rapid deletion of antigen-specific CD4+T cells following infection represents a strategy of immune evasion and persistence for Anaplasma marginale. J Immunol 181:7759-7769

49. Oliveria JB, Madruga CR, Schenk MAM, Kessler RH, Miguita M, Araújo FR (2003) Antigenic characterization of Brazilian isolates of Anaplasma marginale. Mem Inst Oswaldo Cruz 98:395-400

50. De Fuente J, Garcia-Garcia JC, Blouin EF, Kocan KM (2003) Characterization of the functional domain of major surface protein 1a involved in adhesion of the rickettsia Anaplasma marginale to host cells. Vet Microbiol 91:265-283

51. Cantor G, Pontzer C, Palmer GH (1993) Opsonization of anaplasma marginale mediated by bovine antibody against surface protein MSP-1. Vet Immunol Immunopathol 37:343-350

52. Noh SM, Brayton KA, Knowles DP, Agnes JT, Dark MJ, Brown WC, Baszler TV, Palmer GH (2006) Differential expression and sequence conservation of the Anaplasma marginale msp2 gene superfamily outer membrane proteins. Infect Immun 74:3471-3479

53. Kawasaki PM, Kano FS, Tamekuni K, Garcia JL, Marana ERM, Vidotto O, Vidotto MC (2007) Immune response of BALB/C mouse immunized with recombinant MSPs proteins of Anaplasma marginale binding to immunostimulant complex (ISCOM). Res Vet Sci 83:347-354 